\title{
Chemical composition of essential oil from Rosa Damascena mill., growing in new region of Bulgaria
}

\section{Teodora Atanasova ${ }^{1}$, Miroslava Kakalova ${ }^{1}$, Lyubomir Stefanof ${ }^{2}$, Maya Petkova ${ }^{3}$, Albena Stoyanova ${ }^{1}$, Stanka Damyanova ${ }^{4}$, Mykola Desyk ${ }^{5}$}

\author{
1 - University of Food Technologies, Plovdiv, Bulgaria \\ 2 - Lotos Expert Ltd, Plovdiv, Bulgaria \\ 3 - Ekostopanstvo Dunav Ltd, Vidin, Bulgaria \\ 4 - University of Russe, Branch - Razgrad, Bulgaria \\ 5 - National University of Food Technologies, Kyiv, Ukraine
}

Keywords:

Rosa damascena

Essential

Oil

Chemical

Composition

Bulgaria

Article history:

Received 12.06.2016

Received in revised

form 01.08.2016

Accepted 01.09.2016

Corresponding
author:

Stanka Damyanova

E-mail:

sdamianova@

uni-ruse.bg

\section{Abstract}

Introduction. The objectives of this study are to present the chemical composition of essential oils from Rosa damascena Mill., growing in a new region of Bulgaria.

Materials and methods. The rose flowers were harvested in 2016 in the vicinity of the town of Vidin (North-West Bulgaria) in the stage of flowering in two periods - 10 May (sample 1) and 26 May (sample 2).

The chemical composition of the oil is determined chromatographically.

Result and discussion. The moisture of the plants is $82.70 \%$ (for sample 1) and $79.04 \%$ (for sample 2). The yield of essential oil is $0.08 \%$ and $0.03 \%$, respectively.

Thirty-nine components were identified in the oil in sample 1 and sample 2. Two groups of compounds were found in hydro-distillated rose oils, - odor carriers and odor fixators. Terpene alcohols are the main components responsible for the characteristic odor of rose oil and represent about $56 \%$ of total identified substances. High geraniol content with combination of citronellol, farnesol and nerol results in a strong, sweet, floral fresh rosaceous character of the produced rose oils.

The chromatographic profile of the rose oil revealed a significant presence of aliphatic hydrocarbons (31\%) which are the main components responsible for the odor stability.

The main compounds of essential oils were as follows: $\beta$-citronellol (30.24-31.15\%); trans-geraniol (20.62$21.24 \%)$, n-heneicosane (8.79-9.05\%), n-nonadecane (8.51$8.77 \%)$, nonadecene (4.42-4.55\%) and phenylethyl alcohol (4.04-4.16\%).

Conclusion. For the first time in new region of Bulgaria essential oil from Rosa damasena Mill. was obtained. 


\section{Introduction}

Bulgaria is relatively small country in South-East Europe and located in the centre of the Balkan Peninsula. The climate ranges from moderate continental in the northern part to the Mediterranean (subtropical in southwest and southeast regions). As a result of the climatic conditions, soils and other natural factors, Bulgaria has been a producer of rose oil from Rosa damascena Mill for more than 400 years. The rose plants were cultivated in Central Bulgaria in the "Valley of the Roses" which is between the towns Karlovo and Kazanlik (350 m elev.) [1].

Rosa damascena Mill. is the most common in Rosaceae family and the aromatic products are used many different industries such as perfume, cosmetic, pharmaceutical and food. The plant is cultivated and used in Bulgaria, Turkey, Iran, India, China, Libya and other countries [1].

The industrial processing of rose sets its beginning in the middle of 17th century century probably from the Damascus area of Syria. The rose area decreased almost by $50 \%$ - from about 2500 ha in 1990 to about $30000 \mathrm{dka}$ in 2011. Currently, the Bulgarian essential oil industry employs about 12000 people full-time. During the months May to September, the total number involved in cultivation and processing operations increases to 40000.

The essential oil is deposited mostly in the petal leaves (about 93\% of the total content of the flowers) - in the cells of the epidermis and the parenchyma. The average oil content in the flowers is $0.035 \%$, but varies among varieties from $0.009 \%$ to $0.062 \%$ [1]. Roses are known to pass through six phases of flower development from bud-forming to fading, and the transition between each of the stages brings about changes in the quantity and the composition of the essential oil.

In full bloom (Phase IV) the oil content is maximum $(0.071 \%)$, and the content of terpene alcohols (totaling 43\%) is highest, while the amount of stearoptene is minimum $(16 \%)$. With the lowest content of terpene alcohols and the highest of stearoptene are characterized the oils from just-opening buds (Phases I and II). The excess presence of buds and overblown blossom in the processed raw material delivers essential oil with modified composition, i.e. non-standard oil.

Rose oil is an oily, clear liquid or a heterogeneous mass, with yellow to yellow-green color and specific odor. Approximately 400 oil components have been identified. About $62-77 \%$ terpene compounds are found in oil's composition: hydrocarbons (monoterpenes up to $2 \%$ and sesquiterpenes $3-5 \%$ ), oxygen-containing derivatives (monoterpenes $64-71 \%$ and sesquiterpenes $0.5-2 \%$ ), fatty hydrocarbons and their oxygen derivates $(18-25 \%)$, phenylpropanoids (3-5\%), and others $(0.5-2 \%)$ [1].

The distillation itself is the simple process of 'water-distillation'. The flowers are soaked in water and are distilled in containers of $1,2,5$ to $10 \mathrm{~m}^{3}$. The distillate separates continuously in a Florentine flask into water and oil (the so-called 'direct oil'). The water phase, containing emulsified oil and dissolved polar components, yields by a second distillation, involving cohobation, the so-called 'water-oil' and rose water. The two types of oil are mixed together to form the final product, known as rose oil.

The annual production of rose oil in Bulgaria over the last 18 years has varied between 750 to $1900 \mathrm{~kg}$, except for the poor weather year of $2002 \mathrm{t}$ hat yielded only $620 \mathrm{~kg}$. The peak rose oil output of $1650 \mathrm{~kg}$ over the last 30 years occurred in 1975-76. Along with the maturation of the new rose plantations, our aim is to achieve an annual production of 1400 $1500 \mathrm{~kg}$ of rose oil in the next $3-4$ years. 
Rose oil composition is varied over the different conditions, for example harvesting period [2], ecological factors [3, 4, 5, 6, 7] etc. [8, 9, 10]. It is known that the rose essential oil has an antimicrobial activity $[5,9]$.

The essential oil is extensively applied in perfumery, cosmetics and medicine. Rose essential oil is distinguished by a multifaceted pharmacological activity - it is used in the treatment of gall stones, in cases of impaired lipid metabolism; it performs antisclerotic, antispasmodic, and hepatoprotective actions [1].

The objectives of this study are the following: to present the chemical composition of essential oils from Rosa damascena Mill., growing in a new region of Bulgaria; comparing of the obtained results with composition of rose oil standardized in ISO 9842:2006 in order to validate their quality.

\section{Materials and methods}

Materials. The rose flowers were harvested in 2016 in the vicinity of the town of Vidin (North-West Bulgaria, 150-200 m elev.) in the stage of flowering in two periods - 10 May (sample 1) and 26 May (sample 2).

Sample preparation. The oils were prepared by hydrodistillation for $2 \mathrm{~h} 30 \mathrm{~min}$ in laboratory glass apparatus of British Pharmacopoeia, modified by Balinova and Diakov [12]. The oils were dried over anhydrous sulfate and stored in tightly closed dark vials at $4^{\circ} \mathrm{C}$ until analysis.

Moisture content measurement. The row materials moisture content was determined by drying up to constant weight, at $105{ }^{\circ} \mathrm{C}$. The water content is expressed as the percentage, by weight, of the dry sample [11].

Chemical compositon determination. GC analysis was performed using gas chromatograph Agilent 7890A; column HP-5 ms (30 m x $250 \mu \mathrm{m} \times 0.25 \mu \mathrm{m})$; temperature: $35^{\circ} \mathrm{C} / 3 \mathrm{~min}, 5^{\circ} \mathrm{C} / \mathrm{min}$ to $250^{\circ} \mathrm{C}$ for $3 \mathrm{~min}$, total $49 \mathrm{~min}$; carrier gas helium $1 \mathrm{ml} / \mathrm{min}$ constant speed; split ratio 30:1. GC/MS analysis was carried out on a mass spectrometer Agilent 5975C, carrier gas helium, column and temperature as the same as the GC analysis. The components of the oils were identified by their retention indices and by comparison of their mass spectra whit those of authentic samples or with data already available in the literature.

Statistical analysis. Variance analysis of the results was carried out by least square method with application of Microsoft Office Excel program. Differences were considered statistically significant if probability was greater than $95 \%(q<5 \%)$. Experimental results are represented according to standard rules.

\section{Results and discussion}

The moisture of the plants is $82.70 \%$ (for sample 1) and $79.04 \%$ (for sample 2). The yield of essential oil is $0.08 \%$ and $0.03 \%$, respectively.

Chemical compositions of the oils are listed in Table 1.

Thirty-nine components representing $96.61 \%$ of the total content were identified in the oil in sample 1 . Ten of them were in concentrations over $1 \%$ and the rest 29 constituents were in concentrations under $1 \%$. As seen the major constituents (up 3\%) of the oil are as 
follows: $\beta$-citronellol (30.24\%); trans-geraniol (20.62\%), n-heneicosane $(8.79 \%)$, nnonadecane $(8.51 \%)$, nonadecene $(4.42 \%)$ and phenylethyl alcohol $(4.04 \%)$.

A total of thirty-nine components representing $99.54 \%$ of the total content were identified in the oil in sample 2. Ten of them were in concentrations over $1 \%$ and the rest 29 constituents were in concentrations under 1\%. As seen the major constituents (up 3\%) of the oil are as follows: $\beta$-citronellol (31.15\%); trans-geraniol $(21.24 \%)$, n-heneicosane $(9.05 \%)$, n-nonadecane $(8.77 \%)$, nonadecene (4.55\%) and phenylethyl alcohol $(4.16 \%)$.

Chemical composition of rose oils, $\%$

Table 1

\begin{tabular}{|c|c|c|c|c|c|c|c|}
\hline Compounds & $\mathbf{R} \mathbf{I}^{\mathbf{a}}$ & $\begin{array}{l}\text { Sample 1 } \\
\text { (10 May) }\end{array}$ & $\begin{array}{l}\text { Sample } 2 \\
\text { (26 May) }\end{array}$ & Compounds & $\mathbf{R} \mathbf{I}^{\mathbf{a}}$ & $\begin{array}{l}\text { Sample 1 } \\
\text { (10 May) }\end{array}$ & $\begin{array}{l}\text { Sample } 2 \\
\text { (26 May) }\end{array}$ \\
\hline$\alpha$-Pinene & 939 & 0.17 & 0.18 & $\alpha$-Humulene & 1454 & 0.84 & 0.87 \\
\hline Camphene & 954 & 0.13 & 0.13 & $\delta$-Cadinene & 1525 & 0.16 & 0.16 \\
\hline Sabinene & 971 & 0.05 & 0.05 & n-Hexadecane & 1600 & 0.23 & 0.24 \\
\hline$\beta$-Pinene & 979 & 0.43 & 0.44 & 8-Heptadecene & 1683 & 0.18 & 0.19 \\
\hline$\beta$-myrcene & 991 & 0.08 & 0.08 & n-Heptadecane & 1700 & 0.35 & 0.36 \\
\hline Phenylethyl alcohol & 1110 & 4.04 & 4.16 & Farnesyl alcohol & 1725 & 0.21 & 0.22 \\
\hline$\beta$-Linalool & 1097 & 0.85 & 0.87 & n-Octadecane & 1800 & 0.19 & 0.20 \\
\hline cis-Rose oxide & 1106 & 0.16 & 0.18 & Nonadecene & 1880 & 4.42 & 4.55 \\
\hline trans-Rose oxide & 1124 & 0.09 & 0.09 & n-Nonadecane & 1901 & 8.51 & 8.77 \\
\hline Terpinene-4-ol & 1179 & 0.18 & 0.19 & n-Eicosane & 2000 & 2.03 & 2.09 \\
\hline$\alpha$-Terpineol & 1187 & 0.86 & 0.89 & 10-Heneicosene & 2093 & 0.92 & 0.95 \\
\hline$\beta$-Citronellol & 1225 & 30.24 & 31.15 & n-Heneicosane & 2100 & 8.79 & 9.05 \\
\hline cis-Geraniol & 1229 & 3.28 & 3.38 & n-Docosane & 2200 & 0.31 & 0.32 \\
\hline trans-Geraniol & 1248 & 20.62 & 21.24 & (Z)-9-Tricosene & 2294 & 0.55 & 0.57 \\
\hline Citronellyl acetate & 1351 & 0.57 & 0.59 & n-Tricosane & 2300 & 2.22 & 2.29 \\
\hline Geranyl acetate & 1382 & 1.82 & 1.87 & n-Tetracosane & 2400 & 0.15 & 0.15 \\
\hline Eugenol & 1386 & 0.75 & 0.77 & n-Tricosanol-1 & 2495 & 0.26 & 0.27 \\
\hline$\beta$-Elemene & 1390 & 0.42 & 0.43 & n-Pentacosane & 2500 & 0.11 & 0.11 \\
\hline Methyleugenol & 1405 & 0.05 & 0.05 & \multirow[t]{2}{*}{ n-Hexacosane } & \multirow[t]{2}{*}{2600} & \multirow[t]{2}{*}{0.88} & \multirow[t]{2}{*}{0.91} \\
\hline$\beta$-Caryophyllene & 1419 & 0.51 & 0.53 & & & & \\
\hline
\end{tabular}

$\%$, relative percentage of ionic current, ${ }^{\mathrm{a}}$ Retention indices $(\mathrm{RI})$

Two groups of compounds were found in hydro-distillated rose oils, - odor carriers and odor fixators. Terpene alcohols are the main components responsible for the characteristic odor of rose oil and represent about $56 \%$ of total identified substances. 
The chromatographic profile of the rose oil revealed a significant presence of aliphatic hydrocarbons $(31 \%)$ which are the main components responsible for the odor stability (Table 2). Distribution of aroma substances in the two samples shown that the dominant group is oxygen monoterpenes, followed by aliphatic hydrocarbons and phenyl propanoids.

Chromatographic profile of the rose oil, \%

Table 2

\begin{tabular}{|l|c|c|}
\hline \multicolumn{1}{|c|}{ Groups of compounds } & $\begin{array}{c}\text { Sample 1 } \\
\text { (10 May) }\end{array}$ & $\begin{array}{c}\text { Sample 2 } \\
\text { (26 May) }\end{array}$ \\
\hline Aliphatic hydrocarbons & 31.16 & 31.16 \\
\hline Monoterpene hydrocarbons & 0.89 & 0.88 \\
\hline Oxygen monoterpenes & 60.73 & 60.73 \\
\hline Sesquiterpene hydrocarbons & 2.00 & 2.00 \\
\hline Oxigen sesquiterpenes & 0.22 & 0.22 \\
\hline Phenyl propanoids,\% & 5.00 & 5.01 \\
\hline
\end{tabular}

According to qualitative and quantitative content of the major constituents the produced oils are equal to the rose oil (see Table 3).

Citronellol dominates, followed by geraniol and nerol and their concentrations are similar to those regulated by ISO 9842:2006 (Table 3). Citronellol/geraniol ratio was used to evaluating the odor quality of rose oil. A value between $1.25-1.30$ is considered as a reference for the best odor [14].

The data in Table 3 shows that the ratio is 1.47 for the both samples of rose oils which guarantees their excellent properties. High geraniol content with combination of citronellol, farnesol and nerol results in a strong, sweet, floral fresh rosaceous character of the produced rose oils [15].

Comparative chemical composition of rose aromatic products

Table 3

\begin{tabular}{|l|l|c|c|}
\hline No & \multicolumn{1}{|c|}{$\begin{array}{c}\text { Compounds, } \\
\text { \% }\end{array}$} & $\begin{array}{c}\text { Essential oils } \\
\text { (samples 1 and 2) }\end{array}$ & $\begin{array}{c}\text { Essential oil } \\
{[\mathbf{1 3}]}\end{array}$ \\
\hline 1. & Phenylethyl alcohol & $4.04-4.16$ & $\max 3.5$ \\
\hline 2. & Citronellol & $30.24-31.15$ & 31.15 \\
\hline 3. & Nerol & $3.28-3.38$ & $5.0-12.0$ \\
\hline 4. & Geraniol & $20.62-21.24$ & $15.0-22.0$ \\
\hline 5. & Eugenol & $0.75-0.77$ & - \\
\hline 6. & Methyleugenol & 0.05 & - \\
\hline 7. & n-Heptadecane & $0.23-0.24$ & $1.0-2.5$ \\
\hline 8. & n-Nonadecane & $8.51-8.77$ & $8.0-15.0$ \\
\hline 9. & n-Heneicosane & $8.79-9.05$ & $3.0-5.5$ \\
\hline
\end{tabular}


The difference in chemical composition of the our investigations (higher content of nheneicosane and lower of n-heptadecane) and the reported data may be due to environmental conditions under which the plant has grown.

\section{Conclusion}

For the first time in new region of Bulgaria essential oil from Rosa damasena Mill. was obtained. The GC-MS chromatograph profile revealed a significant presence of $\beta$ citronellol (30.24-31.15\%); trans-geraniol (20.62-21.24\%), n-heneicosane (8.79-9.05\%), n-nonadecane (8.51-8.77\%), nonadecene (4.42-4.55\%) and phenylethyl alcohol (4.04$4.16 \%)$.

Bulgaria has the necessary favourable natural conditions, a long production tradition, highly educated professionals and the goodwill to preserve and further develop its essential oils industry. This sector is a one of the priority areas for development in the Bulgarian government economic program.

The industry is export oriented and the Bulgarian companies are making continuous efforts to introduce the best European practice in essential oils production by adoption of EU Directives on manufacturing, quality control, safety and market performance in the branch. Bulgaria today imports large quantities of perfumery and cosmetic products from the well-known international brand name companies.

\section{References}

1. Georgiev E., Stoyanova A. (2006), A guide for the specialist in aromatic industry, Plovdiv.

2. Baydar H., Baydar N. (2005), The effect of harvest date, fermentation duration and Tween 20 treatment on essential oil content and composition of industrial oil rose (Rosa damascena Mill.), Industrial Crops and Products, 5, pp. 251-255.

3. Başer K., Kürkçüoğlu M., Özek T. (2003), Turkish rose oil Research: Recent Results, Perfumer and Flavorist Journal, 3/4, pp. 34-42.

4. Berechet M., Calinescu I., Stelescu M., Manaila E., Craciun G., Purcareanu B., Mihalesku D., Rosca S., Fudulu A., Niculescu-Aron I., Mihai R. (2015), Composition of the essential oil of Rosa damascena Mill. cultivated in Romania, Rev. Chim. (Buharest), 12, pp.1986-1991.

5. Gochev V., Wlcek K., Buchbauer G., Stoyanova A., Dobreva A., Schmidt E., Jirovetz L. (2008), Comparative evaluation of antimicrobial activity and composition of rose oils from various geographic origins, in particular Bulgarian rose oil, Natural Product Communications, 7, pp. 1063-1068.

6. Jirovetz L., Buchbauer G., Shahabi M. (2002), Comparative investigations of essential oils and their SPME headspace volatiles of Rosa damascena from Bulgaria and Rosa centifolia from Marocco using GC/FID, GC/MS and olfactometry, Journal of Essential Oil Bearing Plants, 5, pp. 111-121.

7. Mostafavi A., Afzali D. (2009), Chemical composition of the essential oils of Rosa damascena from two different locations in Iran, Chemistry of Natural Compounds, 1, pp. 110-113.

8. Baydar H., Schulz H., Krüger H., Erbas S., Kineci S. (2008), Influences of fermentation time, hydro-distillation time and fractions on essential oil composition 
of Damask rose (Rosa damascena Mill.), Journal of Essential Oil Bearing Plants, 3, pp. 224-232.

9. Gochev V., Jirovetz L., Wlcek K., Buchbauer G., Schmidt E., Stoyanova A., Dobreva A. (2009), Chemical composition and antimicrobial activity of historical rose oil from Bulgaria, Journal of Essential Oil Bearing Plant, 1, pp. 1-6.

10. Verma R., Padalia R., Chauhan A., Singh A., Yaday A. (2011), Volatile constituents of essential oil and rose water of Damask rose (Rosa damascena Mill.) cultivars from North Indian hills, Natural Products Research, pp. 1577-1584.

11. Russian Pharmacopoeia. (1 $1^{\text {th }}$ Edition), (1990), Moscow.

12. Balinova A., Diakov G. (1974), On improved apparatus for microdistillation of rose flowers, Plant Science, 2, pp. 79-85.

13. ISO 9842:2006. Oil of rose (Rosa $\mathrm{x}$ damascena Miller), p. 12.

14. Baser K.H.C. (1992), Turkish rose oil, Perfum. and Flavor., 17, pp. 45-52.

15. Chinou I. (2013), Assessment report on Rosa gallica L., Rosa centifolia L., Rosa damascena Mill., European Medicines Agency, Committee on Herbal Medicinal Products (HMPC). 